\section{Psicologia Escolar \\ e Educacional}

ARTIGO

DOI: http://dx.doi.org/10.1590/2175-35392020210192

Elocid - e210192

\title{
PERCEPÇÕES DE CRIANÇAS SOBRE PADRÕES DE BELEZA
}

\author{
Juliana Buss $^{1} \mathbb{D}$; Tania Stoltz ${ }^{1} \mathbb{D}$
}

\section{RESUMO}

Há um padrão de beleza hegemônico que circula pela sociedade, afetando a identidade das pessoas. Entretanto, os estudos sobre o tema giram em torno dos adultos. Com isso, é necessário investigar as percepções das crianças acerca dos padrões de beleza, enfatizando suas práticas e falas. Foi realizada uma pesquisa qualitativa e exploratória com 50 crianças (4, 6, 8, 10 e 12 anos), utilizando-se do Método Clínico (Jean Piaget), o qual permite uma investigação profunda. Os participantes foram solicitados a fazer um desenho, ver fotografias e responder a questões relacionadas a padrões de beleza. Notou-se que as crianças têm ideias próprias sobre a beleza e a feiura e que alteram essas percepções de acordo com a idade. Observou-se que os padrões e práticas culturais têm grande influência sobre as crianças, as quais são afetadas pelas mídias, construindo seus discursos através de vivências e aprendizados, tanto da família quanto da escola.

Palavras-chave: beleza; percepção; método clínico.

\section{Perceptions of beauty standards among children}

\begin{abstract}
The hegemonic beauty pattern, which circulates throughout society, affects people's identity. However, studies on the subject revolve around adults. Thus, it is necessary to investigate children's perceptions of beauty standards, emphasizing their practices and speech. A qualitative and exploratory research was conducted with 50 children (4, 6, 8, 10 and 12 years), using the Clinical Method (Jean Piaget), which allows a thorough investigation. Participants had asked to draw, view photographs and answer questions related to beauty standards. It has been noted that children have their own ideas about beauty and ugliness and that they change these perceptions according to age. It was observed that cultural patterns and practices have great influence on children, which are affected by the media, building their discourses through experiences and learning, both inside the family and school.
\end{abstract}

Keywords: Beauty standard; child perception; Piagetian clinical method.

\section{Percepciones de niños sobre el patrón de belleza RESUMEN}

Hay un patrón de belleza hegemónico que circula por la sociedad, afectando la identidad de las personas. Sin embargo, los estudios sobre el tema giran alrededor de los adultos. Con eso, es necesario investigar las percepciones de los niños acerca de los patrones de belleza, enfatizando sus prácticas y hablas. Se realizó una investigación cualitativa y exploratoria con 50 niños (4, 6, 8, 10 y 12 años), se utilizó o Método Clínico (Jean Piaget), el cual permite una investigación profundizada. Se solicitó a los participantes a hacer un dibujo, mirar fotografías y contestar a cuestiones relacionadas a patrones de belleza. Se percibió que los niños tienen ideas propias sobre la belleza y la fealdad y que cambian esas percepciones de acuerdo con la edad. Se observó que los patrones y prácticas culturales tienen gran influencia sobre los niños, los cuales son afectadas por las medias, construyendo sus discursos por intermedio de vivencias y aprendizajes, de la familia y de la escuela.

Palabras clave: Patrón de belleza; percepción infantil; método clínico piagetiano.

\footnotetext{
$\overline{1}$ Universidade Federal do Paraná - Curitiba - PR - Brasil; bussgj@gmail.com; tania.stoltz795@gmail.com
} 


\section{INTRODUÇÃO}

Estudos mostram que o padrão ideal de beleza considerado pelas pessoas é o da magreza, juventude e proporcionalidade (Carvalho \& Serpa, 2014; Freitas, Lima, Costa, \& Lucena Filho, 2010; Kirchof \& Bonin, 2013; Nascimento, Prochno, \& Silva, 2012; Nicolino, 2012; Paixão \& Lopes, 2014; Secchi, Camargo, \& Bertoldo, 2009; Silva, 2012). Os padrões de beleza circulam pela sociedade de diversas formas, seja pela mídia (novelas, propagandas, revistas, filmes), convivência familiar ou institucional, práticas de embelezamento, relações de gênero, brinquedos e histórias literárias, contribuindo fortemente para a construção dos corpos e identidades dos sujeitos (Cechin \& Silva, 2012; Hall, 2000; Louro, 2000).

Esses padrões não são algo simples, natural ou eterno, são construídos cultural e historicamente se modificando de acordo com a cultura e sendo reafirmados pelas mídias, com forte interesse mercadológico (Carvalho \& Serpa, 2014; Cechin \& Silva, 2012; Freitas et al., 2010; Nascimento et al., 2012; Simili \& Souza, 2015; Wolf, 1992) e isso não atinge apenas os adultos. A supervalorização da beleza pela mídia afeta extremamente as crianças, principalmente as do gênero feminino (Carvalho \& Serpa, 2014; Cechin \& Silva, 2012; Kirchof \& Bonin, 2013; Roveri \& Soares, 2011; Silveira Netto, Brei, \& Flores-Pereira, 2010; Simili e Souza, 2015; Xavier Filha, 2016), implantando desejos nas crianças e as caracterizando como fortes consumidoras.

Todavia, grande parte dos estudos feitos sobre beleza e o consumo são focados nos adultos, principalmente nas mulheres (Cruz, 2015; Freitas et al., 2010; Martins, 2016; Nascimento et al., 2012; Paixão \& Lopes, 2014; Secchi, Camargo, \& Bertoldo, 2009; Silva, 2012; Souza, Oliveira, Nascimento, \& Carvalho, 2013; Wolf, 1992) apenas um artigo focaliza os homens (Fontes, Borelli, \& Casotti, 2012). Mesmo os estudos que destacam as crianças ou as culturas infantis (Assunção, Assis, \& Campos, 2012; Carvalho \& Serpa, 2014; Kirchof \& Bonin, 2013; Silveira Netto et al., 2010; Roveri \& Soares, 2011; Simili \& Souza, 2015), trazem um discurso do adulto, ressaltando o papel das mídias na formação dos sujeitos. Apenas Xavier Filha (2016) ressalta as percepções próprias das crianças. Ou seja, os adultos, na maior parte dos textos, estão falando sobre e pelas crianças.

Visto isso, este estudo analisa as percepções das crianças sobre os padrões de beleza, enfatizando como esses padrões influenciam suas vidas e como se internalizam de acordo com a idade. Além disso, será destacado em que medida os padrões de beleza inseridos nas mídias formulam o imaginário e a fala dessas crianças. Acredita-se que, apesar da influência da mídia, há uma cultura infantil com ideias próprias sobre os padrões de beleza, em que as crianças são sujeitos ativos, porém com diferentes percepções de acordo com a idade - a criança como um sujeito epistêmico, que produz conhecimentos (Delval, 2002). Supõe-se também que, quanto maior a criança e mais inserida na cultura, mais os padrões de beleza a influenciam.

Portanto, a discussão dessa temática é fundamental para a educação, tendo em vista que a partir de investigações nessa área, poderão ser criados novos métodos de intervenção, visando fortalecer identidades infantis autônomas, com maior consciência na hora de consumir produtos destinados ao embelezamento.

\section{METODOLOGIA}

\section{Tipo de pesquisa}

Para investigar a percepção das crianças acerca dos padrões de beleza, optou-se por uma pesquisa qualitativa e exploratória de recorte transversal, tendo em vista que permite a compreensão dos conhecimentos e das práticas dos participantes, considerando sua complexidade dentro de um contexto, além de ter como meta descobrir o novo empiricamente (Flick, 2004). Ou seja, a pesquisa qualitativa possibilita que a subjetividade esteja presente, pois explora as ideias próprias dos sujeitos estudados.

Visto isso, houve a utilização do método clínico, no qual há intervenção constante por parte do entrevistador e utilização de contra-sugestões: “... trata-se de apresentar ao sujeito uma explicação distinta ou contrária à sua para ver se persiste nela, o que poderia revelar que sua convicção é firme e não produto de uma sugestão de nossa parte" (Delval, 2002, p. 146). Isto é, as contra-sugestões levam os participantes à reflexão.

No Método Clínico há perguntas básicas comuns para todos os sujeitos, no entanto são ampliadas de acordo com as respostas dos entrevistados, para melhor interpretação - as respostas guiam o curso da entrevista (Delval, 2002). Além disso, o método clínico investiga “... como as crianças pensam, percebem, agem e sentem, que procura descobrir o que não é evidente no que os sujeitos fazem ou dizem, o que está por trás da aparência de sua conduta, seja em ações ou palavras" (Delval, 2002, p. 67).

\section{Contexto e participantes do estudo}

O método clínico permite a realização de estudos evolutivos, ou seja, "... encontrar diferenças nas ideias, nas representações e nas explicações da realidade apresentadas pelos sujeitos de diferentes idades." (Delval, 2002 , p. 101). Com isso, foram escolhidas crianças de quatro, seis, oito, dez e doze anos, a serem completos no ano de 2017, em que, para cada idade, há cinco meninas e cinco meninos, totalizando 50 crianças.

A divisão das crianças em dois gêneros foi feita com o objetivo de investigar se crianças do gênero feminino são as mais afetadas pela supervalorização da beleza, 
tal como aponta a literatura sobre o tema (Carvalho \& Serpa, 2014; Cechin \& Silva, 2012; Kirchof \& Bonin, 2013; Roveri \& Soares, 2011; Silveira Netto, Brei, \& Flores-Pereira, 2010; Simili \& Souza, 2015; Xavier Filha, 2016). Tendo em vista o grande número de sujeitos pesquisados, a escola se mostrou o lugar mais conveniente, além de nesse local as crianças já estarem familiarizadas a interagir com diversos adultos (Delval, 2002).

Feita a autorização da Secretaria da Educação, da escola e dos responsáveis pelos entrevistados, a escolha dos sujeitos ocorreu de forma aleatória e foi necessário explicar que seriam feitas perguntas, que não têm relação com a escola, mas sim que estávamos interessados em descobrir o que pensam. Vale ressaltar que todas as entrevistas ocorreram em instituição pública do município de Curitiba.

\section{Instrumentos e procedimentos de coleta e análise de dados}

Foram feitas observações, registros de trabalho de campo e entrevistas semiestruturadas comuns a todos os sujeitos, as quais seguem as respostas dos entrevistados, fazendo novas perguntas. Além disso, foram utilizados recursos como fotografias e desenhos, visando investigar a percepção das crianças de diferentes formas. Com o intuito de não induzir os sujeitos estudados, foram solicitados que desenhassem uma pessoa bonita antes de ver as fotos, com aplicação do Método Clínico.

As fotografias foram escolhidas cuidadosamente, buscando não induzir as respostas dos entrevistados e não refletir a visão do pesquisador. Tendo em vista a dificuldade de encontrar fotografias com as mesmas características para todas as idades, foram feitos dois conjuntos, um para as idades de 4, 6 e 8, e o outro para as idades de 10 e 12 anos. Cada conjunto continha 10 fotos, cinco de meninas e cinco de meninos. Todos os sujeitos das fotografias estão sorrindo e com roupas simples, para a vestimenta não ser o foco de atenção. Além disso, o cenário das fotografias é neutro.

As crianças/adolescentes das fotografias tinham as seguintes características: 1 ) acima do peso; 2 ) loiro de olho claro; 3) com óculos de grau; 4) afrodescendente; e $5)$ abaixo do peso. Vale ressaltar que nas fotografias " 2 ", as meninas tinham cabelos curtos e os meninos cabelos compridos. A escolha dessas diferentes características das fotos visou o aprofundamento na visão das crianças sobre o que significa beleza, além do desenho.

Para a análise dos dados, foram feitas observações durante as transcrições das entrevistas, visando complementar as respostas dos sujeitos. No entanto, tendo em vista que há uma diversidade de respostas, foi necessário estabelecer categorias, tendo em vista que "Precisamos captar o sentido das explicações que nos proporcionam, os elementos nos quais se apoiam para apresentá-las e como concebem o funcionamento dessa parcela da realidade" (Delval, 2002, p. 162).

No entanto, para chegar a essas categorias, houve necessidade de retirar o máximo de informações dos dados das entrevistas e determinar o que realmente caracteriza o pensamento da criança, mas sem se apegar aos detalhes. Foi indispensável a elaboração de categorias iniciais de análise e a identificação de tendências nas concepções dos sujeitos. Após isso, unido a novas leituras dos protocolos, foi necessário elaborar novas categorias, para examinar se as concepções variaram com a idade das crianças, se são evolutivas e se elas se encaixam nas categorias iniciais (Delval, 2002). Com isso, foi preciso fazer uma análise das categorias, se essas respondem aos objetivos do trabalho.

\section{RESULTADOS E DISCUSSÃO}

\section{Quatro anos - "Eu acho a Melissa bonita porque ela tem uma varinha da Elsa"}

Notou-se, na faixa etária de quatro anos, que as crianças, nos desenhos, relacionaram uma pessoa bonita à afetividade em relação a essa pessoa, desenhando pessoas próximas, como a mãe, o pai, um amigo ou a professora, justificando suas escolhas: "porque... porque eu amo minha mãe" (Renata'). Quando questionados sobre como é uma pessoa bonita, sete participantes afirmaram que é a pessoa que desenharam.

As crianças relacionaram pessoas feias com comportamentos negativos, como morder (Renata), brigar (Maria, Luana, Marina), bater (André, Bruno), falar besteira (Douglas) e fazer bagunça (Davi). Oito crianças afirmaram que aprenderam isso com a professora, 0 irmão, o pai ou a mãe, demonstrando uma moral heterônoma, em que as normas morais ainda não foram reelaboradas pela consciência, sendo apenas a aprendizagem de deveres impostos por adultos (La Taille, 1992).

Em grande parte das questões, os sujeitos de quatro anos mudaram de assunto ou ficaram muito distraídos, manifestando respostas "não-importantes" no seu repertório, as quais se caracterizam pela falta de interesse e distração (Delval, 2002). Nota-se, além disso, que todas as crianças alegaram que acham a si mesmas bonitas e afirmaram que é importante ser bonito.

Quanto às fotos, não houve regularidade em achar as crianças bonitas e nove crianças não acharam nenhuma fotografia feia. Todavia, feita a contra-sugestão, nove crianças mudaram de ideia sobre sua resposta, mas não souberam explicar o motivo, contradizendo suas falas anteriores e demonstrando uma não conservação das ideias:

"Você achou alguma dessas meninas da foto mais bonita? Essa (5). Por quê? Porque eu gosto. É que

\footnotetext{
Todos os nomes utilizados são fictícios, visando proteger a identidade dos participantes.
} 
esses dias eu conversei com uma menina da sua idade e ela me disse que a 2 é a mais bonita porque é loira, o que você acha? Sim, é a mais. Por quê? Porque eu adoro" (Luana, 4 anos).

Algumas crianças aceitaram uma contra-sugestão e recusaram outra, havendo uma variação. Vale ressaltar que duas meninas participantes acharam que o menino " 2 " das fotografias era uma menina, mostrando uma evidência de que a identidade masculina é construída em negação à feminina (Fontes et al., 2012). Além disso, os sujeitos de quatro anos deixaram evidente que outras pessoas não poderiam achar feias as pessoas que eles acharam bonitas. Ou seja, manifestaram um pensamento egocêntrico: “... nosso ponto de vista próprio como absoluto, a nossa perspectiva sobre as coisas como a única possível..." (Piaget, 1998, p. 98).

Seis anos - "As pessoas não podem chamar de feio"

As crianças de seis anos, tal como as de quatro, relacionaram a beleza à afetividade, desenhando pessoas próximas, com a justificativa de que gostam da pessoa. Sete dos participantes disseram que uma pessoa bonita é aquela que brinca e não briga. Três crianças relacionaram com roupas, cabelo e maquiagem: “... quando vai pra uma festa, que fica maquiada, bem linda" (Luisa). Nota-se que houve ampliação nas justificativas, pois sete participantes de quatro anos afirmaram que uma pessoa bonita é quem desenharam.

Para uma pessoa ficar bonita deve colocar uma roupa bonita, pentear o cabelo, tomar banho ou passar maquiagem (Luisa, Mariana, Renan, Benjamin, Raiana, Paulo, Malu e Bruno). Somente duas crianças relacionaram com questões internas, como ser obediente. Uma pessoa feia, para oito crianças, é uma pessoa brava e duas crianças relacionaram com a roupa: "Com uma roupa horrorosa, rasgada, com roupa velha" (Luisa). Vale ressaltar que nove crianças relataram que aprenderam isso com a família ou professora, demonstrando uma moral heterônoma, como as crianças de quatro anos.

Não houve regularidade em achar as crianças das fotos bonitas ou feias, porém Mariana alegou não gostar de pele muito escura, mudando a pele da menina "4" para "Moreninho bem claro" e Bruno destacou que não gosta de pessoas acima do peso, deixando magros os sujeitos " 1 " das fotos. Além disso, todos os participantes afirmaram que nenhuma outra pessoa poderia achar feia quem eles acharam bonita. Isto é, ainda apresentam um pensamento egocêntrico como os sujeitos de quatro anos, em que "... todos pensam ou deveriam pensar como nós” (Piaget, 1998, p. 98). Somente quatro crianças aceitaram as contra-sugestões, passando a achar feio o que achou bonito:

"Você achou alguma feia? Não. É que esses dias eu falei com uma menina da sua idade e ela disse que a 1 é feia por causa da barriga, o que você acha?
É verdade. Por quê? Porque eu não gosto muito de cabelo dourado e gordinha" (Mariana, 6 anos).

Outras discordaram da contra-sugestão, ficando firmes em sua posição. Ou seja, comparado com as crianças de quatro anos, as de seis têm ideias mais bem-estabelecidas. Porém houve aumento no número de sujeitos que pensaram que o menino " 2 " era uma menina.

\section{Oito anos - "Para as pessoas gostarem de você e brincarem com você"}

As crianças de oito anos, tal como as de quatro e seis, desenharam pessoas de seu círculo afetivo, como a mãe, a avó ou um amigo; exceto um menino que desenhou uma menina que vê no recreio e outro menino que não quis desenhar, pois não saberia fazer. Houve ampliação das justificativas dos desenhos em relação aos grupos mais novos: o carinho que sentem pela pessoa (Giovana, Raquel, Joana e João), porque a pessoa é legal (Vinicius), por causa do estilo (Nina) ou não souberam explicar (Giovane, Gabriel e Pietra).

Quando questionadas sobre como é uma pessoa bonita, quatro crianças priorizaram a beleza interior: "Não é bonito por rosto, por roupa, é bonito por dentro mesmo" (Giovana); duas meninas ligaram a beleza a fatores externos: "... maquiada assim, com a roupa nova, roupa bonita" (Raquel) e quatro crianças não souberam explicar. Segundo os participantes, uma pessoa pode ficar bonita colocando uma roupa bonita (Giovana, Pietra, Raquel, Nina e João), cuidando do corpo (Gabriel e Joana), sendo uma pessoa boa (Jean e Vinicius) ou não soube responder (Giovane). Ao contrário dos grupos anteriores, os sujeitos de oito anos começaram a relacionar a beleza a aspectos não visíveis das pessoas.

Na percepção das crianças, uma pessoa feia é aquela que usa roupas rasgadas e não cuida do cabelo (Giovana, Pietra, Raquel e João), é mal-educada (Jean, Joana, Vinicius e Gabriel); duas crianças não souberam responder (Giovane e Nina). Sete crianças alegaram que ninguém ensina o que é ser feio ou bonito e o restante achou que é a professora ou os pais, demonstrando uma transição de moral heterônoma para autônoma. Além disso, sete afirmaram que é importante ser bonito, destacando as relações sociais: "Porque se não, os outros ficam te xingando" (Nina), "Para as pessoas gostarem de você e brincarem com você" (Vinicius).

Quanto às fotos, não houve consenso em achar as crianças feias ou bonitas nem como ficaram dessa maneira, em que as explicações variaram. Porém, três crianças julgaram as fotos feias, baseando-se em algumas características: "Porque o cabelo tá todo espantado" (Giovana, sobre a menina "4") e "Porque eu não gosto de pessoa negra" (João). Vale ressaltar que três crianças apontaram que o menino " 5 " estava muito magro e que duas meninas confundiram o menino " 2 " com 
uma menina, tal como ocorreu nos grupos de quatro e seis anos: "Nossa, cabelo comprido? Bem parecido com uma menina" (Giovana) e "Por causa que tem cabelo que nem menina!" (Joana).

Quando questionados se outra pessoa poderia achar feia a pessoa que eles acharam bonita, os participantes se dividiram: cinco afirmaram que seria possível e cinco afirmaram que seria impossível. Com isso, supõe-se que as crianças de oito anos estão em uma transição, abandonando a visão egocêntrica, característica dos sujeitos de quatro e seis anos.

Sete crianças não aceitaram a contra-sugestão feita pela pesquisadora de que outra criança de oito anos achou os sujeitos " 1 " das fotos feios devido ao tamanho do corpo: "Porque ele tá errado. Todo mundo é do seu jeito" (Giovane), "Por causa que gordo, magro, mais ou menos, fortão... não importa" (Gabriel), "Por causa que isso é bullying" (Nina). É importante enfatizar que os sujeitos dessa idade se mostraram mais atentos aos estereótipos, comparando com os sujeitos mais novos.

Além disso, é importante enfatizar que duas meninas falaram explicitamente sobre bullying, alegando que ocorre na escola e que afeta as pessoas: "Não, quando eu cheguei na escola todo mundo me chamava de gordinha porque eu era. Daí quando eu fiquei de férias eu emagreci uns 5 quilos" (Giovana).

\section{Dez anos - "Porque bem como eu disse, cada um tem seu gosto"}

Todos os participantes de dez anos desenharam muIheres do círculo social, exceto dois que não quiseram desenhar. Suas justificativas foram variadas: a pessoa é uma inspiração (Andressa), uma amiga (Gustavo) ou pelo jeito de se vestir (Mayara). De acordo com os participantes, uma pessoa bonita é uma pessoa simples (Andressa), inteligente e educada (Breno), que respeita (Beatriz), é legal (Hugo), com estilo e postura (Kaique), na moda (Felipe), se assemelhando às respostas dos sujeitos de oito anos.

Quando questionados sobre o que uma pessoa tem que fazer para ficar bonita, afirmaram que não precisa fazer nada (Andressa e Gustavo); se arrumar do jeito que gosta (Breno, Kaique e Lorena); com uma roupa bonita (Felipe e Hugo); ser legal (Beatriz); se cuidar (Soraia) e a pessoa ser ela mesma (Mayara). Segundo as crianças, as pessoas aprendem a ficar bonitas em casa, com a família (Breno, Beatriz e Soraia); se olhando no espelho (Mayara); na internet (Hugo) e ficando na moda (Felipe). De acordo com Felipe, as pessoas aprendem a ficar na moda olhando a televisão, concordando com isso, pois "...eu gosto de ficar arrumado e bonito" (Felipe). Ou seja, a mídia cria identificações, desejos, atitudes e fantasias (Nascimento et al., 2012).

Uma pessoa feia, por sua vez, é uma pessoa sem dente (Gustavo); desarrumada e fedida (Felipe); que fuma, porque envelhece muito rápido (Mayara); que não cuida da pele e do cabelo (Soraia) ou pela atitude (Kaique, Beatriz e Hugo). Para uma pessoa ficar feia, ela deve se arrumar mal (Felipe e Kaique); falar mal das pessoas (Beatriz); não se cuidar (Soraia e Hugo); imitar uma pessoa e fazer muita cirurgia plástica (Mayara) ou não soube explicar (Gustavo). Vale ressaltar que três crianças (Andressa, Breno e Lorena) afirmaram que não tem pessoa feia - "Pra mim pessoa feia não existe, pessoa que faz coisa feia existe" (Breno) e "Porque todo mundo é bonito, do seu jeito" (Lorena). Nota-se que os sujeitos dessa faixa etária, em relação aos grupos anteriores, consideram mais aspectos para designar 0 que é feio ou bonito, demonstrando uma ampliação de suas ideias e perspectivas.

Oito crianças dessa faixa etária asseguraram que ninguém ensina o que é ser feio ou bonito, assemelhando-se aos sujeitos de oito anos. Porém, dois participantes afirmaram que aprendem com os pais (Kaique) e com a professora (Beatriz) o sentido de beleza interior, de não fazer coisas erradas. Comparado às crianças de oito anos, houve uma diminuição em achar importante ser bonito, em que apenas três crianças afirmaram, enfatizando as demandas sociais: "... é melhor, se não as pessoas vão ficar julgando" (Gustavo), "... se não as outras pessoas não vão gostar e querer ficar perto de você... Várias pessoas gostam de gente arrumada, bonita" (Felipe) e "Porque ser bonito é mais fácil de achar marido ou mulher né" (Soraia).

Vale ressaltar que essas crianças acham essas dinâmicas sociais erradas, com posicionamentos mais firmes, ao contrário dos sujeitos de oito anos. Os participantes que afirmaram que não é importante ser bonito, disseram que o que importa é a amizade (Kaique) e ser feliz (Beatriz). Notou-se que quatro crianças afirmaram que o que as outras pessoas pensam afeta: "Por exemplo no bullying... algum gordinho, tá sofrendo bullying, ele sofre, não sofre? Ficam chamando de baleia, saco de areia. Daí machuca" (Lorena).

Quanto às fotos, tal como as crianças das faixas etárias anteriores, não houve uma regularidade em achar os sujeitos das fotografias bonitos ou feios. Vale ressaltar que nenhum dos participantes de dez anos aceitou as contra-sugestões de que outra criança de dez anos disse que a pessoa " 1 " era feia pelo tamanho do corpo ou o " 2 " pelo comprimento do cabelo, demonstrando que suas ideias estão bem-estabelecidas "... as pessoas só julgam pela aparência" (Gustavo), "Porque, tipo, eu não sou preconceituoso, mas quem fala e vê gordo assim, nada a ver... Isso é preconceito" (Kaique), "Eu não acho ela feia porque é gorda... todo mundo é bonito do seu jeito, gordo ou magro, não importa" (Lorena), "Porque até homem pode ter cabelo comprido... Porque é o jeito que eles querem ser. E menina também pode ter cabelo curto, igual de menino" (Soraia). 
É importante destacar, em relação aos participantes de dez anos, que "Os sujeitos se tornam muito mais críticos em relação à ordem social existente, emitem juízos sobre o que é certo e o que não é" (Delval, 2002, p. 231). Além disso, todas as crianças afirmaram ser possível alguém achar feia a pessoa que eles acharam bonita, demonstrando um abandono do pensamento egocêntrico, pelo menos nesse aspecto: "É que cada um tem seu gosto" (Breno), "Tem gente que tem outros pensamentos" (Kaique). Nota-se, com isso, que os sujeitos dessa faixa etária tendem a considerar mais possibilidades: "O sujeito é capaz de coordenar pontos de vista e de refletir sobre o possível" (Delval, 2002, p. 231).

12 anos - "Uma pessoa bonita, eu vejo pelo jeito que ela é, sabe? Não pela aparência. Tipo, o caráter dela"

Dentre os dez participantes de 12 anos, três não quiseram desenhar, alegando que não sabem desenhar (Leandro, Ingrid e Anthony). As crianças desenharam alguém que acharam que seria bonito, mas não conhecem (Elaine, Fernando, Leila e Carlos); a cunhada, pelo jeito de tratar os outros (Paula); a si mesma, porque se acha bonita (Joana) e a mãe, porque faz bem para os outros e é bonita (Jonathan), notando-se uma ampliação nas escolhas.

Todos os sujeitos, quando questionados como é uma pessoa bonita ou feia, diferenciaram beleza interna e externa, afirmando que é a interna que importa mais: "... tem a pessoa que tem um cabelo bonito, tem um rosto bonito, isso torna a pessoa bonita por fora, não se sabe por dentro" (Jonathan) e "Beleza não vem só de fora, mas sim do caráter da pessoa. Porque uma pessoa bonita normalmente ela tende a ser educada" (Paula). É possível observar, com isso, que todos os participantes de doze anos consideram aspectos não visíveis nos seus julgamentos: "Em face de um mundo de aparências, os sujeitos começam a levar em conta fenômenos não-visíveis, aspectos ocultos, com o que alguém não pode ater-se apenas às evidências" (Delval, 2002, p. 229).

Para uma pessoa ficar feia ou bonita, oito participantes relacionaram com o cuidado do corpo, como se vestir bem, cuidar da pele e ter higiene, se assemelhando às respostas dos sujeitos de dez anos. Isso mostra a lógica de investimento nos corpos: “... nós os construímos de modo a adequá-los aos critérios estéticos, higiênicos, morais, dos grupos a que pertencemos. As imposições de saúde, vigor, vitalidade, juventude, beleza, força são distintamente significadas" (Louro, 2000, p. 15). Mas vale ressaltar que os participantes também enfatizaram a importância de tratar os outros bem, de realizar boas ações.

Metade das crianças disse que é importante ser bonito, destacando as demandas sociais: "Tipo, ou as pessoas falam que você é feia, você é julgado por pala- vras, te tiram dos meios de amizade, não te convidam pra fazer trabalho junto" (Joana), "Hoje em dia está sendo muito importante, porque as pessoas bonitas, até no emprego... As pessoas bonitas ganham cargo melhor" (Jonathan), "Porque... as pessoas bonitas têm mais chance tipo... de conseguir um namorado, um emprego" (Leila). Demonstrando, com isso, a percepção de que a aparência é supervalorizada (Fontes et al., 2012).

Duas das crianças enfatizaram que é importante ser bonito por dentro, não por fora (Anthony e Paula). As crianças que não acham importante ser bonito destacaram que "A única coisa que tem que ser é ser legal com os outros, ser si mesmo. E aprender que não existem diferenças entre as pessoas" (Elaine). Comparado às crianças de dez anos, houve aumento em achar importante ser bonito; contudo, as respostas se assemelham no conteúdo.

Os sujeitos entrevistados de 12 anos, tal como os participantes mais novos, não tiveram uma regularidade em achar as fotografias bonitas ou feias ou se mudariam algo nos sujeitos das fotografias ou em si mesmos. Além disso, tal como os sujeitos de dez anos, permaneceram não aceitando as contra-sugestões, alegando: "Que nem eu disse, eu não tenho preconceito. Se é magra, é gorda, é... alta, baixa, pra mim não tem preconceito. Eu vejo as pessoas por dentro" (Jonathan), "... não acho isso, porque isso é um preconceito. Se você achar a pessoa gorda, ela pode ser a pessoa mais legal que você vai conhecer na sua vida" (Fernando), "Olha, eu sofro muito preconceito porque, da minha família (começa a chorar)... a minha tia sofre muito preconceito por ser gorda... porque as pessoas julgam o livro pela capa, sem conhecer a pessoa? Eu não acho isso certo" (Paula), "Porque elas pensam que pessoa bonita é só magrinha, que tipo, não usa óculos... esses tipos de preconceito, entendeu?" (Leila), "... as pessoas têm muito preconceito hoje em dia. Como eu disse, o corpo não muda nada" (Ingrid).

Além disso, tal como os sujeitos de dez anos, afirmaram que outras pessoas poderiam ter outras opiniões sobre o que é bonito ou feio, exaltando o preconceito: "... têm pessoas que são muito preconceituosas, só porque são gordas ou porque são morenas ou porque são loiras. Daí depende da pessoa..." (Elaine), "Por causa do preconceito. Da pessoa gorda, da pessoa loira, da pessoa que usa óculos, da pessoa negra e da pessoa muito magra" (Fernando), "Primeiro pelo preconceito, porque ela (1) é gorda, porque essa (5) é bem magra... também pela cor da pele, alguém poderia achar essa (4) feia por causa da cor da pele dela, que é um pouco escura" (Paula). Ou seja, a partir das falas dos sujeitos, notou-se que há uma aparência hegemônica que circula na sociedade, perceptível às crianças.

Notou-se que os sujeitos de 12 anos têm falas mais 
elaboradas, exemplificando com situações: "Hoje em dia se a pessoa vê uma pessoa que é negra, às vezes ela é muito discriminada" (Joana), "Eu acho isso uma falta de respeito, porque tem um programa de TV que uma pessoa se veste do jeito que ela gosta todos os dias, e eles vão lá e mudam, jogam as roupas da pessoa no lixo e colocam outras" (Jonathan), "Esse (fotografia 3) provavelmente, que acontece muito em série de TV, pode ter passado por um momento ruim por usar óculos" (Fernando), "Que nem aqui no 70 A tem um menino com cabelo comprido e ele é muito zoado por isso, eu não acho isso certo, porque isso é uma coisa pessoal dele" (Paula). Nota-se, com isso, que os comentários sobre bullying expressam vivências no cotidiano dos entrevistados, em que "A violência, seja ela psíquica ou física, é a expressão maior do exercício do poder" (Azevedo et al., 2012, p. 251).

\section{CONSIDERAÇÕES FINAIS}

Foi possível constatar que a família e a escola contribuem para a formação dos conceitos de "bonito" e "feio" em todas as faixas etárias. A partir das falas dos sujeitos de dez e doze anos, nota-se que a mídia está presente na formação desses conceitos. Todavia, no processo de formação dos conceitos de "bonito" e "feio" há a atividade do sujeito cognitivo, que processa essas informações de modo único.

Notou-se a tendência ao aumento da complexidade das percepções das crianças no decorrer dos anos, demonstrando um processo evolutivo. As meninas, com seis e oito anos, defendem mais as práticas de embelezamento, como o uso de maquiagem. As mais velhas, de dez e doze anos, por sua vez, passam a se empoderar, defendendo que isso não é algo obrigatório, essencial a todas as mulheres. Os meninos de doze anos, da mesma forma, defendem que as pessoas devem ser como elas querem. Vale ressaltar, no entanto, que não houve diferenças significativas quanto ao gênero dos participantes em todas as faixas etárias.

Tanto meninos quanto meninas de quatro, seis e oito anos defenderam que cabelo comprido é coisa de menina. Portanto, notou-se que as ideias dos sujeitos evoluíram e ficavam mais elaboradas aos dez e doze anos. Vale ressaltar que, nas entrevistas e na análise de dados, foi manifestado o quanto as crianças são ativas, produzem conhecimentos e têm ideias próprias, as quais se alteram de acordo com a idade. Há, portanto, influência da família, escola e mídia, e, ao mesmo tempo, construção das representações sobre as vivências, em que "... a estrutura do organismo interage com o meio externo para se reconstituir e criar uma nova significação para o sujeito" (Stoltz, 2008, p. 20).

Todavia, quanto maiores os sujeitos e mais inseridos na cultura, mais os padrões de beleza culturais e suas práticas influenciam, tendo em vista os relatos de bullying e preconceito presentes nas falas dos sujeitos de oito, dez e doze anos. Conclui-se que, apesar de não haver um padrão em considerar as fotografias bonitas ou feias, esses relatos surgiram a partir delas, possibilitando um aprofundamento nas percepções das crianças.

Nota-se que as práticas de bullying ocorrem voltadas para os corpos dos sujeitos, sugerindo que, de fato, a identidade vai se construindo a partir do corpo, o qual está completamente inserido nas relações sociais. E, apesar das crianças de dez e doze anos trazerem uma visão crítica acerca desses temas, notou-se que essas práticas acontecem na escola.

Portanto, a escola torna-se um local privilegiado para tratar desses assuntos, problematizando-os. É necessário, de acordo com Silva (2000), uma pedagogia crítica e questionadora, voltada para as diferenças, em que a pedagogia oportunize aos sujeitos o desenvolvimento de críticas e questionamentos acerca das formas de representação dominantes da identidade e da diferença. Isto é, as crianças podem assim perceber que os padrões de beleza são produzidos, ligados às relações sociais de poder e de representação.

É importante destacar, todavia, que o estudo foi limitado a um contexto e a poucas crianças, sendo necessário um maior aprofundamento com mais sujeitos, para confirmar regularidades evolutivas. E, a partir dos relatos sobre bullying causado pela aparência dos indivíduos, é possível desenvolver pesquisas problematizando o papel das escolas e das famílias nessas situações, bem como propor práticas que fortaleçam a reflexão sobre as identidades das crianças e suas ideias sobre padrões de beleza, para evitar atitudes violentas e desenvolver atitudes que questionem padrões. Nesse sentido, torna-se fundamental o trabalho qualificado com as diferenças, na escola e na família.

\section{REFERÊNCIAS}

Assunção, C. Q. S.; Assis, R. M.; Campos, R. H. F. (2012). Belos, sadios e normais: as representações sociais dos corpos infantis na revista Pais \& Filhos (1968-1977). Revista Brasileira de Ciências do Esporte, 34, 571-587. doi: 10.1590/S0101-32892012000300005

Azevedo, J. C.; Miranda, F. A.; Souza, C. H. M. (2012). Reflexões a cerca das estruturas psíquicas e a prática do Ciberbullying no contexto da escola. Intercom: Revista Brasileira de Ciências da Comunicação, 35, 247-265. doi: 10.1590/ S1809-58442012000200013

Carvalho, I. A.; Serpa, M. G. (2014). Corpo e Embelezamento: a Criança Participante de Concurso de Beleza. Psicologia: Ciência e Profissão, 34, 835-849. doi: 10.1590/1982370001432013

Cechin, M. B.; Silva, T. (2012). Assim falava Barbie: uma boneca para todos e para ninguém. Fractal: Revista de Psicologia, 24, 623-638. doi: 10.1590/S1984-02922012000300012

Cruz, D. F. C. (2015). Seguindo as tramas da beleza: cabelos 
na centralidade estético-corporal de Maputo*. Cadernos Pagu, 45, 135-156.doi: 10.1590/18094449201500450135

Delval, J. (2002). Introdução à prática do método clínico descobrindo o pensamento das crianças (Murad, F., Trad). Porto Alegre: Artmed.

Flick, U. (2004). Uma introdução à pesquisa qualitativa (Netz, S. Trad.). Porto Alegre: Bookman. (Trabalho original publicado em 2002).

Fontes, O. A.; Borelli, F. C.; Casotti, L. M. (2012). Como ser homem e ser belo? Um estudo exploratório sobre a relação entre masculinidade e o consumo de beleza. REAd. Revista Eletrônica de Administração,18, 400-432. doi: 10.1590/ S1413-23112012000200005

Freitas, C. M. S. M.; Lima, R. B. T.; Costa, A. S.; Lucena Filho, A. (2010). O padrão de beleza corporal sobre o corpo feminino mediante o IMC. Revista Brasileira de Educação Física e Esporte, 24, 389-404. https://www.revistas.usp.br/rbefe/ article/view/16775/18488

Hall, S. (2000). Quem precisa de identidade? In Silva, T. T. (Ed.), Identidade e diferença: a perspectiva dos estudos culturais (pp. 103-133). Petrópolis, RJ: Vozes.

Kirchof, E. R.; Bonin, I. T. (2013). Representações do feio na literatura infantil contemporânea. Educação $e$ Realidade, 38, 1069-1088. http://seer.ufrgs.br/index.php/ educacaoerealidade/article/view/38157

La Taille, Y. (1992). Desenvolvimento do juízo moral e afetividade na teoria de Jean Piaget. In La Taille, Y.; Oliveira, M. K.; Dantas, H. (Eds.), Piaget, Vygotsky, Wallon: teorias psicogenéticas em discussão (pp. 47-73). São Paulo: Summus.

Louro, G. L. (2001). Pedagogias da sexualidade. In Louro, G. L. (Ed.), O corpo educado pedagogias da sexualidade. (2a. ed.) (pp. 7-34). Belo Horizonte: Autêntica.

Martins, M. C. (2016). “E a Bela dançou...": subvertendo o belo feminino dos contos de fadas. Revista Estudos Feministas, 24, 351-363. doi: 10.1590/1805-9584-2016v24n1p351

Nascimento, C. M.; Prochno, C. C. S. C.; Silva, L. C. A. (2012). O corpo da mulher contemporânea em revista. Fractal: Revista de Psicologia, 24, 385-404. doi: 10.1590/S198402922012000200012.

Nicolino, A. S. (2012). Primazia da beleza feminina e juventude empobrecida: notas de uma relação conflituosa. Interface - Comunicação, Saúde, Educação, 16, 83-94. doi: 10.1590/

\section{S1414-32832012005000013.}

Paixão, J. A.; Lopes, M. F. (2014). Alterações corporais como fenômeno estético e identitário entre universitárias. Saúde em Debate, 38, 267-276. doi: 10.5935/01031104.20140024.

Piaget, J. (1998). Pedagogia. (J. Chaves, trad.). Coleção Horizontes Pedagógicos/Éditions Odile Jacob.

Roveri, F. T.; Soares, C. L. (2011). Meninas! sejam educadas por Barbie e "com" a Barbie... Educar em Revista, (41), 147-163. doi: 10.1590/S0104-40602011000300010.

Secchi, K.; Camargo, B. V.; Bertoldo, R. B. (2009). Percepção da imagem corporal e representações sociais do corpo. Psicologia: Teoria e Pesquisa, 25, 229-236. doi: 10.1590/ S0102-37722009000200011.

Silva, A. L. S. (2012). Imperativos da beleza: corpo feminino, cultura fitness e a nova eugenia. Cadernos CEDES, 32, 211222. doi: 10.1590/S0101-32622012000200007.

Silva, T. T. (2000). A produção social da identidade e da diferença. In Silva, T. T. (Ed.), Identidade e diferença: a perspectiva dos estudos culturais (pp. 73-102). Petrópolis, RJ: Vozes.

Silveira Netto, C. F.; Brei, V. A.; Flores-Pereira, M. T. (2010). O fim da infância? As ações de marketing e a "adultização" do consumidor infantil. Revista de Administração Mackenzie, 11, 129-150. http://editorarevistas.mackenzie.br/index. php/RAM/article/view/1589/2486.

Simili, I. G.; Souza, M. C. (2015). A beleza das meninas nas "dicas da Barbie". Cadernos de Pesquisa, 45, 200-217. doi: $10.1590 / 198053142878$

Souza, M. R. R.; Oliveira, J. F.; Nascimento, E. R.; Carvalho, E. S. S. (2013). Droga de corpo! Imagens e representações do corpo feminino em revistas brasileiras. Revista Gaúcha de Enfermagem, 34, 62-69. doi: 10.1590/S198314472013000200008

Stoltz, T. (2008). As perspectivas construtivista e históricocultural na educação escolar. (2ª ed.). Curitiba: Ibpex.

Wolf, N. (1992). O mito da beleza: como as imagens de beleza são usadas contra as mulheres (W. Barcellos, trad.). Rio de Janeiro: Rocco. (Trabalho original publicado em: 1991).

Xavier Filha, C. (2016). Gênero e resistências em filmes de animação. Pro-Posições, 27, 19-36. doi: 10.1590/01037307201607902.

A Pesquisa contou com bolsa produtividade do CNPq n. 311402/2015-1 e com bolsa de iniciação científica do CNPq.

Recebido: 01 de agosto de 2018

Aprovado: 21 de janeiro de 2019 